\title{
BLOOD TRANSFUSION IN THE MALNUTRITION OF INFANCY
}

BY

\author{
MAGNUS L. THOMSON, M.A., M.B., Ch.B.(Aber.), \\ Late Resident Medical Officer, Royal Manchester Children's Hospital; \\ Medical Registrar, Salford Royal Hospital.
}

The treatment of the marasmic infant is not the least difficult of the many perplexing problems which confront the paediatrician. If cases showing evidence of organic disease and those where the feeding is either unsuitable or mismanaged be excluded, there are still those infants whose constitution is such that neither skilful feeding nor expert nursing can coax them along the highroad to health. Such children are the despair of both parent and doctor. It is for these infants that blood transfusion is a worthy adjunct to routine methods, as illustrated by the following results. Used as an emergency measure in the extreme stages of enteritis, the results are often disappointing. The fact that one such patient, apparently moribund when transfused, is now a healthy baby, demands that all measures be tried even when the cause seems lost. The group of cases where blood transfusion was employed soon after the onset of enteritis show distinctly favourable results.

When the condition of malnutrition remained uncomplicated, blood transfusion led to an immediate and sustained gain in weight. These infants had failed to respond to routine treatment over a long period. No addition to the treatment was made either following the transfusion or for some days previous to it. Five patients with severe enteritis died. All the others to whom blood was given have subsequently done well. The results afford evidence that in most cases blood transfusion does supply a stimulus to the marasmic infant. The precise nature of the stimulus is not clear. Blood transfusion may act (a) by sujpplying physiological fluid; (b) by supplying a deficiency of one or more of the solid contents of the blood; and (c) by exciting a tissue response in the bone marrow or elsewhere.

Once the marasmic infant ' turns the corner,' the subsequent prognosis is favourable. These results are presented, with the belief that blood transfusion may supply that added stimulus which sets the infant on the path to recovery. No suggestion is made that blood transfusion should replace routine methods. 
Carefully performed, blood transfusion is a procedure devoid of risk. In this series there were no unfavourable reactions or sequelae. In most of the cases one of the parents acted as donor, and in every case the recipient's serum was tested directly against the donor's corpuscles. The serum and corpuscles were left in contact for twenty minutes before a decision was made on the compatability of the bloods. In two instances the baby's serum agglutinated the mother's corpuscles and one of these was a baby aged six weeks - an indication of how early in life the blood groups may be distinctly differentiated.

\section{Method}

The blood was obtained from the donor by means of a large-bore needle which had previously been washed through with sterile sodium citrate solution. A suitable vessel containing a quantity of 3.8 per cent. sodium citrate solution received the blood, which was then put aside in a basin containing warm water and gently stirred until required. One part of citrate solution was used for nine parts of blood. On one occasion a specimen containing this proportion of citrate and blood was set aside for twenty-four hours. At the end of that period the whole quantity was passed, without difficulty, through a fine hypodermic needle. The syringe used to transfer the blood from the container to the vein was of the Jube pattern with a barrel capacity of 5 c.c. It may be noted that for this type of work the gravity method is entirely unsuitable, as it requires too great a head of pressure to run the blood into the small vein of an infant. A blunted hypodermic needle was employed for insertion into the recipient's vein in place of a cannula. The whole apparatus was washed through with citrate solution and laid aside ready for use.

Exposure of THE vein.-A short length of the internal saphenous vein was dissected out at the ankle under local anaesthetic and a temporary ligature tied at the lower limit of dissection. A second, loosely tied ligature was placed round the vein at the upper limit of dissection. The vein was then incised longitudinally to avoid the risk, inherent in a transverse incision, of a complete division. The apparatus was then filled with blood, the cannula inserted into the vein and the transfusion begun.

When the required amount had been transfused the cannula was withdrawn and both ligatures removed. The skin incision was sutured and haemorrhage controlled by a pad and bandage over the wound. By this method an attempt was made to avoid permanent occlusion of the vein.

As it was considered advisable that the blood be given slowly, a minimum period of fifteen minutes was set for the transfusion of the blood, however small the quantity used. For this reason, the indirect method was used exclusively in the younger infants, the direct method being employed in older children.

Definite rules cannot be laid down as to the quantity of blood given. On an average 10 to 15 c.c. per pound of body weight forms a safe guide. In cases showing extreme degrees of dehydration larger quantities may be given with safety. In babies who are malnourished rather than dehydrated the lower limit is probably best. 
The results are embodied in the following tables and certain cases are described individually.

\section{Group 1. Cases complicated by severe enteritis.}

(BLOOd transfusion phrformed as an EMergenct measure).

\begin{tabular}{|c|c|c|c|c|c|c|c|}
\hline \multirow[t]{2}{*}{ Casi no. } & \multirow{2}{*}{$\begin{array}{c}\text { AGE } \\
\text { IN } \\
\text { WEEKS }\end{array}$} & \multicolumn{2}{|c|}{$\begin{array}{l}\text { WEIGHT } \\
\text { ON } \\
\text { ADMISSION }\end{array}$} & \multirow{2}{*}{$\begin{array}{c}\text { PERIOD BETWREN } \\
\text { ADMISSION } \\
\text { AND ONSET OF } \\
\text { ENTERITIS } \\
\text { IN DAYS }\end{array}$} & \multirow{2}{*}{$\begin{array}{c}\text { PERIOD BETWEEN } \\
\text { ONSET OF ENTERITIS } \\
\text { AND BLOOD } \\
\text { TRANSFOSION } \\
\text { IN DAYS }\end{array}$} & \multirow{2}{*}{$\begin{array}{c}\text { AMOUNT } \\
\text { OF } \\
\text { BLOOD : } \\
\text { c.c. }\end{array}$} & \multirow[t]{2}{*}{ RESULT } \\
\hline & & & oz. & & & & \\
\hline 1 & 4 & 5 & 1 & 8 & 6 & 90 & Death \\
\hline 2 & 7 & 6 & 6 & 15 & 2 & 75 & Death \\
\hline 3 & 12 & 7 & 4 & $\begin{array}{l}\text { ENTERITIS ON } \\
\text { ADMISSION }\end{array}$ & 3 & 60 & Death \\
\hline 4 & 5 & 4 & 14 & 23 & 3 & 100 & Death \\
\hline 5 & 12 & 7 & 12 & 21 & 10 & 50 & Death \\
\hline 6 & 5 & 6 & 0 & 36 & 5 & 75 & RECOVERY \\
\hline Averages & 8 & 6 & 3 & 17 & 5 & 57 & - \\
\hline
\end{tabular}

Death occurred at an average of sixty hours after transfusion.

Following transfusion in case 6 , vomiting was completely arrested and the stools improved progressively. There was no marked gain in weight until seven weeks later when lactic acid and Nestlé's feeds were instituted. Eleven weeks after operation the baby was discharged weighing $9 \mathrm{lb} .6 \mathrm{oz}$. The result in this case was dramatic. 


\section{Group 2. (A) Cases complicated by enteritis of less severity.}

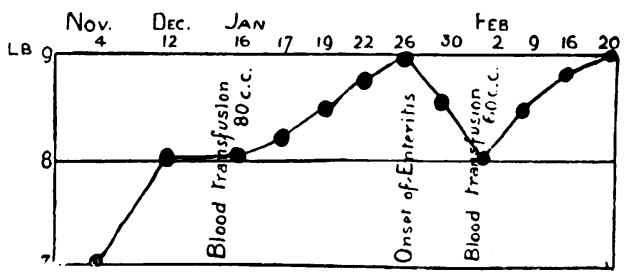

Case 7.-Malnutrition, aged Three weeks. Subsequent progress satisfactory.

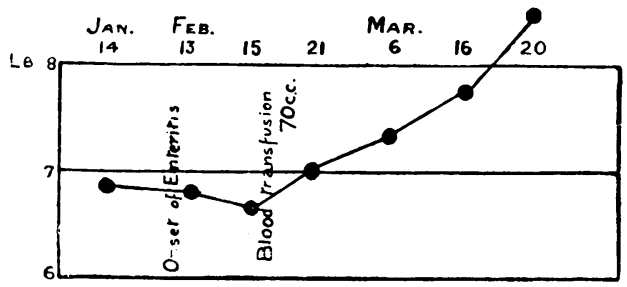

Case 8.-Malnutrition, aged Six weeks. Subsequent progress satisfactory.

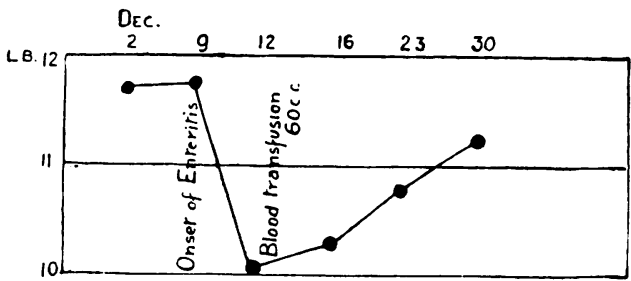

Case 9.-Malnutrition, aged four months. Subsequent progress satisfactory.

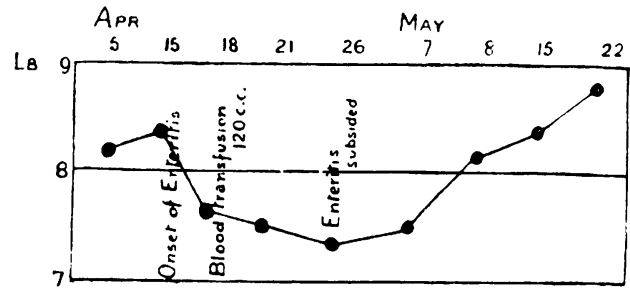

Case 10.-Malnutrition, aged eleven weeks.

This case appeared to derive no benefit from blood transfusion. Progress followed subsidence of the enteritis and the addition to the the feeds (milk and water) of Benger's. Subsequent progress satisfactory.
Group 2. (B) Cases complicated by other conditions.

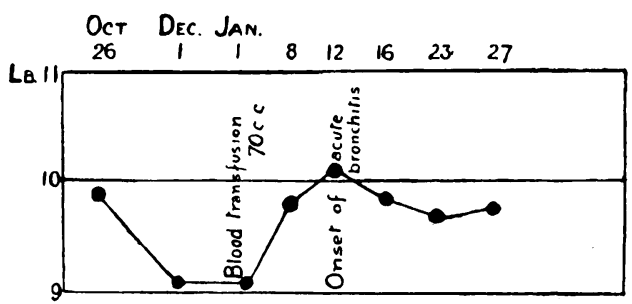

Case 11.-Malnutrition, aged Five months, COMPLICATED BY ACUTE BRONCHITIS.

Subsequent progress satisfactory. The attack of bronchitis caused a temporary check in the progress following transfusion.

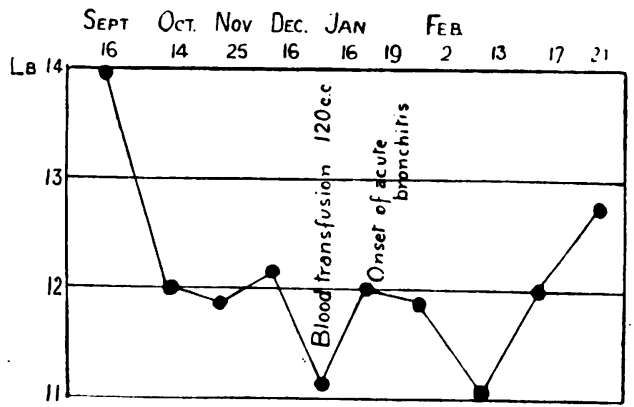

Case 12.-Malnutrition, aged Seven months, COMPLICATED BY ACUTE BRONCHITIS.

Improvement following transfusion checked by onset of acute bronchitis. Subsequently made good progress.

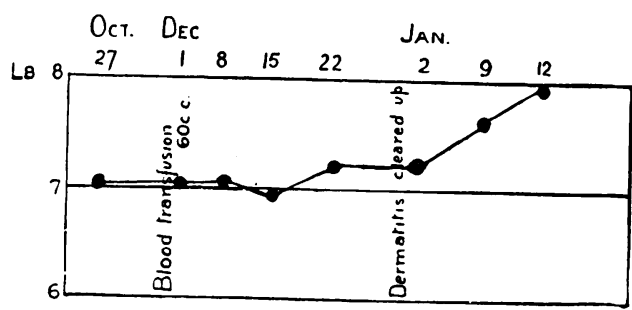

Case 13.-Malnutrition, aged SIX WeEks, COMPLICATED BY CHRONIC DERMATITIS.

Blood transfusion did not appear to benefit this case. Subsequent progress satisfactory. 
Group 3. Uncomplicated cases of malnutrition.

\begin{tabular}{|c|c|c|c|c|c|c|c|c|c|c|}
\hline \multirow[t]{2}{*}{ Case No. } & \multirow{2}{*}{$\begin{array}{c}\text { AGE } \\
\text { IN } \\
\text { WEEKS. }\end{array}$} & $\begin{array}{l}\text { Period Betwifen } \\
\text { ADMISSION } \\
\text { AND TRANSFUSION }\end{array}$ & \multirow{2}{*}{$\begin{array}{c}\text { AMOUNT } \\
\text { OF BLOOD } \\
\text { GIVEN } \\
\text { IN C.C. }\end{array}$} & \multicolumn{2}{|c|}{$\begin{array}{l}\text { ADMISSION } \\
\text { WEI(XHT }\end{array}$} & \multicolumn{2}{|c|}{$\begin{array}{l}\text { WEIGHT at } \\
\text { OPERATION }\end{array}$} & \multicolumn{2}{|c|}{$\begin{array}{l}\text { DischaRge } \\
\text { WEIGHT }\end{array}$} & \multirow{2}{*}{$\begin{array}{c}\text { GAIN PER } \\
\text { DAY AFTER } \\
\text { OPERATION } \\
\text { IN OZ. }\end{array}$} \\
\hline & & IN DAYS & & LB. & oz. & IAB. & oz. & LR. & oz. & \\
\hline 14 & 7 & 24 & 70 & 5 & 2 & 5 & 4 & 6 & 10 & $0 \cdot 88$ \\
\hline 15 & 24 & 52 & 110 & 12 & 2 & 11 & 10 & 12 & 14 & 0.66 \\
\hline 16 & 7 & 33 & 120 & 5 & 6 & 5 & 4 & 6 & 6 & 0.82 \\
\hline 17 & 10 & 17 & 110 & 7 & 8 & 7 & 6 & 8 & 10 & $1 \cdot 05$ \\
\hline 18 & 5 & 44 & 60 & 6 & 4 & 6 & 12 & 7 & 6 & 0.71 \\
\hline 19 & 10 & 21 & 65 & 5 & 8 & 5 & 6 & 7 & 4 & 0.88 \\
\hline 20 & 9 & 47 & 70 & 6 & 0 & 6 & 4 & 7 & 10 & 0.59 \\
\hline Averaties & 8 & $30 \frac{1}{2}$ & 85 & 6 & 15 & 6 & 11 & 8 & $1 \frac{1}{2}$ & 0.8 \\
\hline
\end{tabular}

In all these seven cases, the gain in weight after operation was sustained and the starting point coincided with the operation. The average period from operation to discharge was twenty-five days.

Composite Weigh't chart of the above CASES.

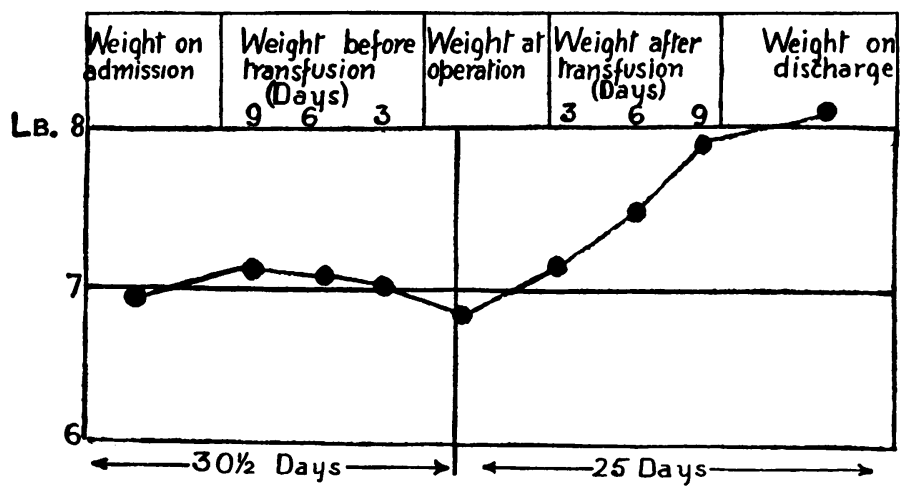

In the normal child the average gain in weight in the first twelve months is four ounces per week. In these seven cases the gain per week from operation to discharge was five-and-half ounces.

\section{Survey of results.}

If a gain in weight is taken as the criterion of improvement, blood transfusion was successful in twelve of the twenty cases. Excluding the five 
fatal cases there were a further two cases where no apparent benefit followed. In these it is impossible to assess what part transfusion played. In case 6 , despite the fact that no gain in weight followed the operation, the clinical improvement was so impressive as to leave no doubt, in the minds of those associated with the case, that transfusion had been a life-saving procedure. The results in uncomplicated cases of malnutrition (group 3), are suggestive, without being entirely conclusive. Proof must await trial in a large number of cases. It is suggested that blood transfusion is a remedy of value in uncomplicated cases of chronic malnutrition.

\section{Summary.}

(a) In the advanced stage of acute enteritis blood transfusion should be a routine measure. A favourable response can be expected only in a small proportion of such cases.

(b) In the marasmic infant, blood transfusion should be employed as soon as the condition of acute enteritis supervenes.

(c) In uncomplicated cases of malnutrition blood transfusion is a valuable measure. A favourable response may be expected in a large percentage of such cases.

I am indebted to the Honorary Medical Staff of the Royal Manchester Children's Hospital for their kind permission to publish these results. 